\title{
Mitos e controvérsias sobre a política de cotas para negros na educação superior ${ }^{*}$ \\ Myths and controversies on the policies of quotas for blacks in higher education
}

\author{
Mariluce Bittar** \\ Carina E. Maciel de Almeida***
}

\begin{abstract}
RESUMO
Neste texto, analisa-se o processo de implantação da política de cotas para negros na educação superior, tomando como base a implementação dessa política na Universidade Estadual de Mato Grosso do Sul - UEMS. Investigou-se, também, em que medida o sistema de reserva de vagas para negros pode ser considerado uma estratégia de acesso e permanência dos estudantes negros na educação superior. Para atingir tal objetivo, foram entrevistados alunos que ingressaram, pelo sistema de cotas para negros, no Processo Seletivo de 2004 da UEMS nos cursos de Direito e Enfermagem e analisados documentos e legislações referentes à implantação desse sistema na UEMS. Os dados revelaram que os alunos negros compreendem o sistema de cotas como um direito e que a permanência nos cursos depende de ações efetivas, por parte da Universidade, como bolsas de estudo e apoio pedagógico. As cotas representam uma ação afirmativa no sentido de se garantir o respeito à diversidade racial e a superação das desigualdades historicamente construídas. Palavras-chave: política de cotas; educação superior; acesso e permanência.
\end{abstract}

"Agências Financiadoras: CNPq; FUNDECT.

*** Doutora em Educação (UFSCar); Coordenadora do Programa de Pós-Graduação Mestrado em Educação da Universidade Católica Dom Bosco - UCDB; Coordenadora do Grupo de Estudos e Pesquisas sobre Políticas de Educação Superior - GEPPES; bittar@ucdb.br

**** Mestre em Educação (UCDB); Doutoranda em Educação (UFMS); pesquisadora do GEPPES; carina.em@pop.com.br 
BITTAR, M.; ALMEIDA, C. E. M. Mitos e controvérsias sobre a política de cotas...

\begin{abstract}
In this text the process of implantation of the politics of quotas for blacks in the higer education is analyzed, taking as base the implementation of this politics in the State University of Mato Grosso do Sul - UEMS. It was investigated, also, where measured the system of vacant reserve for blacks it can be considered a strategy of access and permanence of the black students in the higer education. To reach such objective, pupils who had entered, for the system of quotas for blacks in the Selective Process of 2004 of the UEMS, in the courses of right and nursing had been interviewed, and analyzed referring documents and legislations to the implantation of this system in the UEMS. The data had disclosed that the black pupils understand the system of quotas as a right and that the permanence in the courses depends on action effective, on the part of the University, as pedagogical support and scholarships. The quotas represent an affirmative action in the direction of if guaranteeing the respect to the racial diversity and the overcoming of the inaqualities historicamente constructed.

Key-words: politic of quotas; higher education; access and permanence.
\end{abstract}

\title{
Introdução
}

A política de cotas para negros na educação superior no Brasil tem despertado debate intenso, especialmente porque, via de regra, essas discussões trazem, de forma implícita ou explícita, concepções de racismo e discriminação presentes na sociedade brasileira. As ações de algumas universidades em relação a essa política têm sido desenvolvidas de forma isolada, uma vez que a política de cotas para negros não está regulamentada oficialmente e, conseqüentemente, não é obrigatória nas IES públicas e privadas.

A luta do homem contra a discriminação racial teve suas origens nas idéias defendidas pela Independência Americana, em 1776, e na Revolução Francesa, em 1789, no surgimento dos ideais democráticos e, principalmente, na luta dos homens pelos seus direitos naturais. "Consideramos essas verdades como sendo auto-evidentes, que todos os homens são criados iguais, que eles são dotados pelo Criador com certos direitos inalienáveis, que entre esses (direitos) estão a vida, a liberdade e a busca da felicidade", 
proclamou a Declaração de Independência Americana em 1776 (FUNDAÇão Cultural palmares, 2005). Com os ideais de "Liberdade, Fraternidade e Igualdade" da Revolução Francesa, a Declaração dos Direitos do Homem e do Cidadão, promulgada pela Assembléia Nacional Francesa, em 1789, afirmava que todos os homens eram iguais perante a lei; portanto, esses movimentos também podem ser caracterizados como embriões de combate ao racismo no mundo.

A história da resistência negra no Brasil teve seu início com a vinda dos primeiros negros trazidos da África, em meados do século XVI. Posteriormente, houve resistência organizada, como a Revolta dos Malés, na Bahia, e a instituição da República de Palmares na Serra da Barriga, em Alagoas, reduto que durou até 1695, com a morte de Zumbi dos Palmares. Por volta da década de 1940, organizou-se a chamada Frente Negra de Combate ao Racismo. Nos períodos ditatoriais, houve grande resistência ao Movimento Negro. Sob alegação de infringência à Segurança Nacional, esses governos taxavam esse movimento social de subversivo, equiparando-o à ideologia comunista. Em 1968, a ONU (Organização das Nações Unidas) aprovou a Convenção para a Eliminação de Todas as Formas de Discriminação Racial, ${ }^{1}$ que foi ratificada por 157 países, os quais se comprometeram a promulgar e proteger os princípios de igualdade. A ONU promoveu também três Conferências Mundiais sobre essa temática, sendo as duas primeiras em Genebra (Suíça), em 1978 e 1983, e a terceira em Durban (África do Sul), em 2001. Esta última Conferência abordou temas mais abrangentes: racismo, discriminação racial, xenofobia e intolerância correlata, objetivando erradicar qualquer forma de discriminação racial.

Dentre as bandeiras de luta de todos esses movimentos anti-raciais destaca-se o direito à educação, discriminação racial como "qualquer distinção, exclusão, restrição ou preferência baseada em raça, cor, descendência ou origem nacional ou étnica, com o propósito de anular ou prejudicar o reconhecimento, benefício ou exercício de direitos humanos e liberdades fundamentais" (Fundação Cultural Palmares - BR, 2005). 
BITTAR, M.; ALMEIDA, C. E. M. Mitos e controvérsias sobre a política de cotas...

de conscientização por meio do qual os negros aprenderiam a história de seus ancestrais, os valores e a cultura de seu povo, podendo a partir destes reivindicar direitos sociais e políticos, direito à diferença e respeito humano (GONÇALVES, 2000, p. 337).

A política de cotas para negros na educação superior é decorrência de todos esses movimentos e é vista como um "projeto de reparações", para inserir os negros no meio social. É nesse contexto que se inserem as análises e os dados de pesquisa aqui apresentados; esses resultados são oriundos de projeto de pesquisa que contou com o apoio do CNPq e da FUNDECT (Fundação de Apoio e Desenvolvimento do Ensino, Ciência e Tecnologia do Estado de Mato Grosso do Sul). Seu objetivo consistiu em analisar o processo de implantação da política de cotas para negros na educação superior na Universidade Estadual de Mato Grosso do Sul - UEMS - e em que medida essa política pode ser considerada uma estratégia de acesso e permanência dos estudantes cotistas na Universidade. Para alcançar tal objetivo, foram entrevistados os alunos que ingressaram pelo sistema de cotas para negros no Processo Seletivo 2004 (vestibular realizado em dezembro de 2003) nos cursos de Direito e Enfermagem do campus da UEMS localizado na cidade de Dourados, Mato Grosso do Sul. Além disso, foram analisados documentos e legislações concernentes à implantação das cotas na referida Universidade.

\section{Desigualdades raciais na sociedade, na educação e na educação superior}

De acordo com Marcelo Paixão, no Brasil os negros detêm apenas 4\% dos rendimentos no país (somando salário, aposentadorias, programas de renda mínima e aplicações financeiras); os pardos, 21,9\%; e os bran$\cos , 74,1 \%$. O autor afirma que esse panorama da economia no país "é um exercício para pensar como a desigualdade e a pobreza no Brasil têm um evidente componente racial. A riqueza está concentrada entre os brancos, enquanto, entre os pobres, a maioria é negro" (PAIX̃̃o, 2003, C3). 
Até o final do século XIX, mais precisamente 1872, o país registrava a existência de leis que proibiam o acesso de negros e negras, livres ou libertos, à escola de qualquer nível, lembrando que a criação dos primeiros cursos de nível superior data do início do século XIX. Daí porque não é a mesma coisa ser branco pobre e negro pobre no Brasil [grifos nossos] (RIBEIRO, 2003, A3).

No Brasil, $45 \%$ da sua população é negra; $63 \%$ dos brasileiros com renda mensal inferior a um salário mínimo são negros e, dos 22 milhões de indigentes, 69\% são negros (FUNDAÇÃo CULTURAL PALMARES, 2005). O Índice de Desenvolvimento Humano (IDH) coloca o Brasil na 69 posição em relação aos outros 182 países, considerado como "IDH Médio". Porém, ao se fazer o recorte racial, a situação se agrava: ao se considerar os índices relativos à população negra, a posição cai para $101^{\mathrm{a}}$, o que corresponde ao "IDH Médio-baixo". No entanto, ao se considerar apenas a situação dos não-negros, a posição do Brasil sobe para $46^{\mathrm{a}}$ posição (FOLHA DE SÃO PAULO, 2003, C4.), o que o classifica como "IDH Alto". Esses dados indicam que a população negra encontra-se em condição social, econômica e educacional inferior aos demais segmentos da população, uma vez que, ao ser realizado o recorte racial, separando a população negra da população branca, o IDH nacional é alterado significativamente.

De acordo com Almeida (2003), “(...) somos o país com a segunda maior população negra do mundo - mais de 79 milhões de afrodescendentes, ficando atrás somente da Nigéria". Entretanto, apenas 2,8\% de alunos negros concluem o ensino superior (INEP, 2006); a desigualdade entre negros e brancos que concluem o ensino superior é significativa (cf. Quadro I) e a superação dessa situação requer ações públicas imediatas. Segundo Munanga (2003a),

... se por milagre o ensino básico e fundamental melhorar seus níveis para que os alunos desses níveis de ensino possam competir igualmente no vestibular com os alunos oriundos dos colégios particulares bem abastecidos, os alunos negros levariam cerca de 32 anos para atingir o atual nível dos alunos brancos. 
BITTAR, M.; ALMEIDA, C. E. M. Mitos e controvérsias sobre a política de cotas...

O mesmo autor afirma que o Brasil é um país

\begin{abstract}
... onde os preconceitos e a discriminação racial não foram zerados, ou seja, onde os alunos brancos pobres e negros pobres ainda não são iguais, pois uns são discriminados uma vez pela condição socioeconômica e outros são discriminados duas vezes pela condição racial e socioeconômica... (MUNANGA, 2003b, p. 119).
\end{abstract}

Segundo o Censo da Educação Superior, de 2002, 2.864 .046 brasileiros estavam cursando esse nível de ensino; desses, 2.249.155 eram bran$\cos (78,5 \%) ; 68.208$, negros $(0,23 \%) ; 37.403$, de cor amarela; 491.698, pardos $(1,61 \%)$; 4.397, indígenas e 13.185, de cor ou raça ignorada (FolHA DE SÃO PAULO, 2003, C4). Isto é, somadas as percentagens de negros e pardos $(1,84 \%)$, ainda assim é um valor, representativamente, muito abaixo do percentual das vagas ocupadas por brancos. No que se refere à escolaridade concluída, os dados indicam que são os amarelos que detêm o maior percentual de nível superior completo: $26,9 \%$; os pardos somam $2,4 \%$; os indígenas $2,2 \%$; os negros $2,1 \%$ e, os brancos, $9,9 \%$, o que representa, aproximadamente, quatro vezes mais que cada um desses três. Na Pós-Graduação (stricto sensu), 86,4\% são brancos; 9,2\% são pardos; $1,9 \%$ são amarelos; $1,8 \%$ são negros e $0,2 \%$, indígenas (IBGE, 2005).

Com relação às diferenças entre anos de estudo e desempenho escolar, constatou-se que a participação dos jovens negros na última série do ensino médio representa $50 \%$ da registrada na $4^{\mathrm{a}}$ série do ensino fundamental, enquanto os brancos, que somam $44 \%$ dos alunos ao final do primeiro ciclo do fundamental, totalizam $76 \%$ na $3^{\text {a }}$ série do ensino médio (MEC/INEP/SEEC, 2003).

Segundo dados do INEP (MEC/INEP/SEEC, 2003), alunos brancos, matriculados na $4^{a}$ série (rede pública e particular) - filhos de mães com escolaridade até a $8^{a}$ série do ensino fundamental - obtiveram média de desempenho de 175 pontos em matemática, contra uma média de 160 de estudantes negros filhos de mães com a mesma escolaridade. Essa diferença de 15 pontos entre as médias de desempenho aumenta para 38 quando se comparam brancos com mães de escolaridade média ou superior, com alunos negros com mães de mesma escolaridade. Mesmo entre estudantes de escolas particulares, portanto com níveis socioeconômicos similares, o de- 
sempenho entre brancos e negros não é igual. $\mathrm{Na} 4^{\mathrm{a}}$ série, em língua portuguesa, alunos negros alcançaram uma pontuação de 179 na escala de desempenho, e os brancos de 228 pontos.

Os resultados obtidos de uma prova de linguagem não são somente o feito de estudantes caracterizados por sua formação anterior, sua origem social, seu sexo, ou mesmo todos esses critérios considerados simultaneamente, mas de categoria que, pelo próprio fato de ser dotada do conjunto dessas características, não sofreu a eliminação no mesmo grau que uma categoria definida por outras características (BOURDIEU, 1982, p. 81-82).

Bourdieu esclarece que o desempenho escolar não é resultado apenas da formação dos alunos e da origem social da qual eles advêm, mas também de uma série de fatores que condicionam sua participação na escola. Sob este enfoque, podem-se associar a discriminação e marginalização dos negros no contexto social, principalmente na escola; a discriminação opera como fator aditivo na operação de exclusão desses alunos do processo educativo. Implica afirmar que, para ter acesso ao nível superior, esses fatores deveriam estar sanados, sob pena de fracasso do processo escolar. Portanto, o meio social como um todo é condicionante da ascensão social do indivíduo.

Ainda que valores como igualdade e solidariedade, respeito ao próximo e às diferenças estejam presentes no discurso da escola, outros mecanismos, talvez mais sutis, revelam que preconceitos e estereótipos também integram o cotidiano escolar. Os veículos da discriminação vão desde o currículo formal, que exclui múltiplas e variadas maneiras de expressão cultural, passando pela linguagem não-verbal, até chegarem, freqüentemente, ao nível dos comportamentos e das práticas explícitas (SAAVEDRA, 2003, p. 24).

Dados recentes publicados pelo MEC/INEP (2006) reforçam essas análises, ao compararem a presença de "brancos", "pardos" e "negros" na sociedade e no campus, além de evidenciarem o número de ingressantes e concluintes nesses mesmos segmentos populacionais: 
BITTAR, M.; ALMEIDA, C. E. M. Mitos e controvérsias sobre a política de cotas...

QUADRO I

\begin{tabular}{|c|c|c|c|c|}
\hline & $\begin{array}{c}\text { Presença na } \\
\text { Sociedade }\end{array}$ & $\begin{array}{c}\text { Presença no } \\
\text { Campus }\end{array}$ & Ingressantes & Concluintes \\
\hline Brancos & $50 \%$ & $72,9 \%$ & $70,2 \%$ & $76,4 \%$ \\
\hline Negros & $41 \%$ & $20,5 \%$ & $22,3 \%$ & $17,5 \%$ \\
\hline Pardos & $5,9 \%$ & $3,8 \%$ & $4,6 \%$ & $2,8 \%$ \\
\hline
\end{tabular}

FONTE: MEC/INEP, http://www.inep.gov.br/informativo/informativo130.htm, ACESSO EM: 10 DE MARÇO DE 2006.

Observa-se que a taxa de sucesso de negros e pardos é significativamente menor que a de brancos, ou seja, somados os dois segmentos, pardos e negros (definição do IBGE), estes representam 46,9\% da sociedade, mas estão presentes no campus apenas $24,1 \%$, enquanto entre os brancos essa presença aumenta para 72,9\%, embora, na sociedade, sejam $50 \%$ do total. Com relação aos ingressantes, os brancos somam 70,2\%, enquanto negros e pardos representam $26,9 \%$, mas a tendência ainda diminui ao se observarem os dados dos concluintes, pois os brancos representam $76,4 \%$ e os negros e pardos, $20,3 \%$.

A discussão das cotas para negros na educação superior surge nesse contexto. Há possibilidade de existir "classe média negra" no Brasil, levando em consideração que essas pessoas sequer chegam à educação superior? Os dados evidenciam que a população negra tem menos acesso à educação, principalmente à superior, uma vez que existem os exames seletivos para o ingresso.

\section{Ações afirmativas para negros na educação superior - o exemplo da Universidade Estadual de Mato Grosso do Sul - UEMS}

A UEMS foi criada pela Constituição Estadual de 1979 e ratificada pela Constituição de 1989, conforme os termos do disposto no artigo 48 do Ato das Disposições Constitucionais de 1989, e foi instituída pela Lei $\mathrm{n}^{\circ}$ 1.461 , de 20 de dezembro de 1993, com sede e foro na cidade de Dourados. Desde sua origem, delineou-se a preocupação de “(...) uma proposta 
de universidade voltada para as necessidades regionais, objetivando superálas e contribuindo, por meio do ensino, da pesquisa e da extensão para o desenvolvimento científico, tecnológico e social do estado" (UEMS, 2003). Entre as necessidades regionais, foi destacado o grande número de pessoas negras e indígenas que residiam no estado e que não tinham acesso à educação superior. Segundo dados do IBGE, do ano de 2000, o Estado de Mato Grosso do Sul possuía 71.139 negros de um total de 2.078.070 habitantes, o que representava $3,42 \%$ da população sul-mato-grossense. Do total de negros, 19,3\% (13.700) são analfabetos. Em relação à educação superior, o estado contava com 745 estudantes negros cursando a educação superior (desses, 38 na pós-graduação stricto sensu), ou seja, 0,035\% em relação ao total de negros. No cenário nacional, os estudantes brancos totalizavam $21,9 \%$, enquanto os negros apenas $5,7 \%$. Ao se compararem dados nacionais com dados regionais e estaduais, é interessante notar que a região Centro-Oeste apresentava média superior à do Brasil: 25,9\% de estudantes brancos para 9,9\% alunos negros; por sua vez, Mato Grosso do Sul apresentava percentual mais elevado de estudantes brancos, 27,6\%, enquanto os negros representavam $8,2 \%$, revelando uma distância maior entre brancos e negros. Interessante observar que o quantitativo de alunos que concluem os cursos de educação superior no Brasil cai tanto para negros como para brancos: estes somam 9,9\%, enquanto os negros totalizavam apenas $2,1 \%$; o grande percentual de concluintes pertence aos "amarelos" (segundo definição do IBGE), cujos concluintes representam 26,9\% do total no país (IBGE, 2000).

Diante dessa situação de desigualdade, no final dos anos 1990 e início dos anos 2000 os movimentos sociais organizados de Mato Grosso do Sul pressionaram os poderes públicos a formularem políticas que visassem a modificação de tais indicadores. Assim, a discussão da política de cotas no estado ocorreu, principalmente, por pressão do movimento negro, que exigia a implantação do sistema de cotas nas universidades públicas. A conquista ocorreu somente no ano de 2003, quando o deputado estadual Pedro Kemp, após memorável sessão pública na Assembléia Legislativa Estadual, conseguiu aprovação, por unanimidade, da proposta de implantação do sistema de cotas na Universidade Estadual de Mato Grosso do Sul, por meio da Lei ${ }^{\circ}$ 2.605/03, de 06/01/2003. A justificativa que assentou sua proposição foi a seguinte: 
BITTAR, M.; ALMEIDA, C. E. M. Mitos e controvérsias sobre a política de cotas...

Na Constituição Federal está expresso o princípio da igualdade de direitos, sendo papel do Estado promover o bem-estar social sem preconceitos de origem, raça, cor, idade e quaisquer outras formas de discriminação. No entanto, por mais que na Lei conste expresso o repúdio a qualquer tipo de discriminação, vimos na prática a não superação do racismo. O Relatório da Rede Social de Justiça e Direitos Humanos, feito em parceria com a Global Exchange, afirma que 'a população negra brasileira é a segunda maior do mundo após a Nigéria', e o Brasil foi o último país ocidental a abolir a escravidão. Aimensa desigualdade racial tem sua origem no processo de colonização. (...) O quadro de desigualdade social entre negros e brancos está relacionado tanto a fatores estruturais quanto à discriminação. Entre os fatores estruturais, sem dúvida, o mais significativo é o componente educacional. Ao se situarem nos grupos com menor acesso à educação formal, os negros também ocupam postos de menor prestígio no mercado de trabalho. Nesse sentido, é preciso que o Estado invista em políticas públicas afirmativas, invertendo a lógica da estrutura de oportunidades, que está profundamente marcada por práticas violadoras de direitos e de discriminações baseadas na raça $\left(\right.$ LEI N $\left.^{\circ} 2.605 / 03,2003\right)$.

A questão da "igualdade de direito" consiste num ponto polêmico, pois alguns autores, contrários à implantação de cotas, apegam-se a esse princípio constitucional alegando que essa política fere a igualdade de direito dos cidadãos. José Goldemberg assim se manifestou em artigo da Folha de São Paulo:

Com as cotas no sistema educacional, especialmente de forma a assegurar aos pobres e negros condições de permanência e sucesso na escola (uma vez que o acesso está praticamente garantido), a reprovação e o abandono constituirão o verdadeiro gargalo para o ingresso na universidade, pois o percentual dos que logram concluir o ensino médio continuará a ser muito inferior ao dos brancos e orientais (...).Adotar cotas, pura e simplesmente, além da evidente dificuldade de distinguir brancos e negros num país com ampla miscigenação como o Brasil, é uma medida certeira para degradar o nível das universidades públicas e que não vai resolver séculos de discriminação econômica e racial (2004, A3).

Mesmo reconhecendo que a questão remete ao fato de que o problema maior "(...) é a pobreza que atinge amplos setores da sociedade brasilei- 
ra e em especial os negros", Goldemberg enfatiza que a implementação de cotas nas universidades públicas "(...) é perigoso e ilegal, pois contraria frontalmente a autonomia universitária (...)". O autor refere-se à Constituição Brasileira (1988) e à Lei de Diretrizes e Bases da Educação (1996), que respaldam o princípio da autonomia universitária e conclui: "Num país democrático, boas intenções não podem servir de pretexto para desrespeito à lei" (GOLDEMBERG, 2004, A3).

Outra manifestação vem do juiz federal Mauro Spalding, que considerou ilegal e uma "(...) afronta ao princípio da isonomia (...)" a reserva de 40\% das vagas da Universidade Federal do Paraná, no vestibular realizado em 2004. Atendendo a um mandado de segurança de um estudante reprovado no vestibular, que requeria o direito de se matricular no lugar de um estudante negro aprovado pelo sistema de cotas, o juiz concedeu liminar positiva respaldando-se no referido princípio. Na mesma matéria, a opinião de outro juiz choca-se frontalmente com a de Spalding, por entender que a inclusão de negros por esse sistema é que pode possibilitar o seu acesso à universidade pública e gratuita, já que o “(...) sistema educacional do país é perverso por retirar dos carentes a possibilidade de cursar o nível superior gratuitamente." (JUIZ QUESTIONA..., 2005)

No outro pólo dos argumentos encontram-se as reflexões de Gomes. Ao discutir a constitucionalidade das ações afirmativas, o autor as define como:

... políticas públicas (e privadas) voltadas à concretização do princípio constitucional da igualdade material e à neutralização dos efeitos da discriminação racial, de gênero, de idade, de origem nacional e de compleição física. Na sua compreensão, a igualdade racial deixa de ser simplesmente um princípio jurídico a ser respeitado por todos e passa a ser um objetivo constitucional a ser alcançado pelo Estado e pela sociedade (2003, p. 21).

Para tentar desmontar o argumento dos que defendem o princípio jurídico contra a política de cotas, Gomes enfatiza que:

A teoria constitucional clássica, herdeira do pensamento de Locke, Rousseau e Montesquieu, é responsável pelo florescimento de uma 
BITTAR, M.; ALMEIDA, C. E. M. Mitos e controvérsias sobre a política de cotas...

concepção meramente formal de igualdade - a chamada igualdade perante a lei. Trata-se em realidade de uma igualdade meramente processual (...). As notórias insuficiências dessa concepção de igualdade conduziram paulatinamente à adoção de uma nova postura, calcada não mais nos meios que se outorgam aos indivíduos num mercado competitivo, mas nos resultados efetivos que eles podem alcançar (2003, p. 37).

Seus argumentos estão assentados em vários artigos da Constituição Brasileira de 1988, os quais, segundo ele, revelam o “(...) repúdio do constituinte pela igualdade processual (...)" e a preocupação com a "(...) igualdade substancial (...)", a qual deve ser assegurada por medidas efetivas de alcance da igualdade material (GOMEs, 2003, p. 38-39). Nesse sentido, defende a adoção de ações afirmativas com sendo uma ação transformadora, fundamentada nos princípios do direito, como uma possibilidade de atingir “(...) a verdade do princípio da igualdade (...) como direito fundamental de todos" (GOMES, 2003, p. 41).

Fundamentada nesse princípio constitucional, a UEMS, a exemplo de outras universidades públicas estaduais, ${ }^{2}$ iniciou a implantação do sistema de cotas em 2003, abrindo amplo processo de discussão com as comunidades interna e externa sobre os critérios a serem estabelecidos para atender ao requisito de reserva de $20 \%$ das vagas para negros em seus cursos de graduação. Os critérios para inscrição no sistema de cotas foram definidos por uma comissão constituída por representantes da UEMS, do Movimento Negro e do Conselho Estadual de Defesa dos Direitos do Negro. ${ }^{3}$ Por sua vez, as inscrições são avaliadas por outra comissão instituída pela Pró-Reitoria de Ensino, composta por representantes da UEMS, do Movi-

${ }^{2}$ Em 2001, foi aprovada a primeira lei brasileira para implantação da política de cotas para negros na educação superior: a Lei 3.708, de 9 de novembro, que determina a reserva de $40 \%$ das vagas dos cursos de graduação na Universidade Estadual do Rio de Janeiro (UERJ) e na Universidade Estadual do Norte Fluminense (UENF). No ano seguinte, a Universidade Estadual da Bahia (UNEB) também implantou o sistema de vagas, destinando $40 \%$ para negros (FOLHA DE SÃo PAULO, 23/5/2002).

${ }^{3}$ As exigências para atender os critérios são: “(...) uma foto colorida recente $5 / 7 \mathrm{~cm}$; autodeclaração, constante na ficha de inscrição; fotocópia do histórico escolar do ensino médio ou atestado de matrícula expedidos pela escola da rede pública de ensino; declaração da condição de aluno bolsista fornecida por instituição da rede privada de ensino, quando for o caso" (CORDEIRO, 2005) 
mento Negro, do Fórum Permanente de Entidades do Movimento Negro de MS e do Conselho Estadual de Defesa dos Direitos do Negro, que defere ou não a inscrição “(...) por decisão fundamentada, de acordo com o fenótipo do candidato” (CORDEIRO, 2005).

Nas entrevistas com os alunos ingressantes pelo sistema de cotas, no vestibular de 2003, foi possível observar suas concepções acerca das cotas como estratégia de acesso e como eles se identificaram como negros:

QUADRO II

\begin{tabular}{|c|c|}
\hline IDENTIFICAÇÃO COMO NEGRO & $\begin{array}{c}\text { COTAS COMO ESTRATÉGIA DE } \\
\text { ACESSO/DIREITO }\end{array}$ \\
\hline $\begin{array}{l}\text { Bati o olho assim [no cartaz da UEMS] } \\
\text { 'você é negro?' Aí já fui atrás de fotos, } \\
\text { porque eu já me identificava com aquela } \\
\text { pergunta. (Entrevista, Aluna B, Direito, } \\
2005 \text { ) }\end{array}$ & $\begin{array}{l}\text { Eu também penso assim: 'se tem na estadual, } \\
\text { vaga por cotas, vou me garantir'. Porque na } \\
\text { federal não tinha, então pensei: 'vou me } \\
\text { garantir'. (Entrevista, Aluno A, Direito, } \\
2005 \text { ) }\end{array}$ \\
\hline $\begin{array}{l}\text { Eufiqueicommedo, porque comentei } \\
\text { comalgumaspessoas e elas disseram: } \\
\text { mas você não é negra, você é uma } \\
\text { moreninha só. Você não chega a ser } \\
\text { negra. Falei: 'gente, negro é o nosso } \\
\text { sangue, não só a nossa cor'. Minha mãe } \\
\text { não é, mas meu pai é negro, o pai do } \\
\text { meu pai era negro; minha mãe fala que } \\
\text { ele era azul de tão preto que era. Então } \\
\text { eu não sou negra? Fiquei com medo de } \\
\text { colocar lá e eles não aceitarem, mas eu } \\
\text { me considero. (Entrevista, Aluna A, } \\
\text { Direito, 2005) }\end{array}$ & $\begin{array}{l}\text { Acho que é excelente para colocação de } \\
\text { pessoas negras nas faculdades públicas. } \\
\text { Acho que facilita, pois o negro não tem tanta } \\
\text { facilidade para entrar. (...) Porque cheguei a } \\
\text { fazerocursinho(pré-vestibular) porcinco } \\
\text { meses na particular, é uma coisa totalmente } \\
\text { diferente da pública, a dinâmica do professor } \\
\text { é totalmente diferente. Então o aluno negro } \\
\text { que sai de uma escola pública, com um } \\
\text { professor mais para lá que para cá, para } \\
\text { concorrer com o que está estudando e que } \\
\text { tem todos esses macetes, é difícil. Então } \\
\text { acho que olhando o sistema de cotas, o aluno } \\
\text { se anima mais a estudar e a competir com } \\
\text { outras pessoas. (Entrevista, Aluna C, } \\
\text { Direito, 2005) }\end{array}$ \\
\hline $\begin{array}{l}\text { Para mim, não tem nem como descrever } \\
\text { sempre tive vontade de estudar, é meu } \\
\text { sonho entrar em uma universidade }(\ldots) \\
\text { então para mim vai ser uma realização } \\
\text { e norme se eu conseguir chegar até o } \\
\text { fim. Não tive problema em me declarar } \\
\text { como negra. Vou conseguir, pois faz } 7 \\
\text { anos que eu luto para isto, não tem } \\
\text { como descrever... (Entrevista, Aluna } \mathrm{A} \text {, } \\
\text { Enfermagem, 2005) }\end{array}$ & $\begin{array}{l}\text { (...) eu pensei 'mas é um direito, vamos } \\
\text { usar'. Foi a primeira coisa que passou pela } \\
\text { minha cabeça (Entrevista, Aluna B, } \\
\text { Enfermagem, 2005). }\end{array}$ \\
\hline
\end{tabular}

FONTE: PESQUISA DE CAMPO, ENTREVISTAS REALIZADAS EM NOVEMBRO DE 2005. 
BITTAR, M.; ALMEIDA, C. E. M. Mitos e controvérsias sobre a política de cotas...

Percebe-se, nas entrevistas, que os motivos que levam pessoas negras a se inscreverem pelo sistema de cotas são resultado de diferentes perspectivas sobre a questão racial e cultural. Muitas vezes a identificação como negro não foi sequer pensada pelos estudantes, mas diante da possibilidade de acesso à educação superior pelo sistema de cotas, tal enfrentamento se faz necessário. Os entrevistados entendem que as cotas são um direito a ser utilizado e implementado para que outros negros tenham oportunidade de acesso à educação superior; alguns estudantes entrevistados haviam tentado várias vezes o vestibular, mas somente com a implantação das cotas foi possível esse acesso.

Um aspecto pouco conhecido pela sociedade refere-se às condições e critérios para o acesso pelo sistema de cotas, pois essas não são distribuídas gratuitamente para os alunos que se inscrevem no processo. Os candidatos que aspiram a uma dessas vagas submetem-se às mesmas provas dos candidatos às vagas gerais e são avaliados da mesma forma e com os mesmos critérios de nota. Assim, o argumento de que a universidade receberá alunos desqualificados e despreparados torna-se frágil. A diferença consiste no fato de que os candidatos às vagas por cotas devem identificarse como tal no ato da inscrição; ao se corrigirem as provas, eles serão classificados separadamente e os que obtiverem notas necessárias para aprovação ocuparão as vagas. Desse modo, são “(...) respeitados os méritos e garantida a excelência no seio de um universo específico" (MUNANGA, 2004, p.59).

No primeiro vestibular para cotas realizado pela UEMS, em dezembro de 2003, os dados revelam que os negros obtiveram notas equivalentes à dos brancos em vários quesitos. Entre eles destacam-se: a) na prova de conhecimentos gerais, $41,4 \%$ dos brancos obtiveram de 20 a 40 pontos e $51 \%$ alcançaram de 40 a 60 pontos; do total de negros, $69 \%$ atingiram de 20 a 40 pontos e $25 \%$ conseguiram de 40 a 60 pontos; b) na prova de conhecimentos específicos, $29 \%$ do total de brancos obtiveram de 20 a 40 pontos e $46 \%$ de 40 a 60 pontos; do total de negros, $58 \%$ alcançaram de 20 a 40 pontos e $27 \%$ completaram de 40 a 60 pontos (CORDEIRO, 2005). As diferenças não são tão significativas e deve-se levar em consideração que os inscritos pelas vagas das cotas precisaram comprovar a conclusão do ensino médio em escola pública, a fim de atenderem aos critérios da Comissão de Seleção. Portanto, o sistema de cotas possibilita uma concorrência mais equiitativa, uma vez que se oferecem condições concretas de igualdade de acesso, pois nas vagas gerais muitos dos que concorrem são provenientes de escolas privadas, colocando-os, automaticamente em posição 
privilegiada para obter aprovação no vestibular. A esse respeito uma dos entrevistados nesta pesquisa assim se manifestou:

É diferente uma pessoa que estudou em escola particular e uma pessoa que estudou a vida inteira em uma escola pública, eu penso que há diferença sim, porque no cursinho que eu participei vi muita coisa que nunca vi na escola, não tinha nem noção, tem diferença sim, quem estudou em escola particular, a maioria são brancos porque aqui todos os cotistas estudaram em escola pública. (Entrevista, Aluna B, Enfermagem, 2005).

Mesmo entrando na universidade com notas pouco abaixo das notas dos brancos, os negros têm condições de acompanhar ou até mesmo superar o rendimento no processo pedagógico, conforme demonstrou pesquisa publicada na Folha de São Paulo:

Na UERJ, primeira universidade de grande porte a adotar a reserva de vagas, os cotistas entraram com nota mais baixa no vestibular, mas tiveram no primeiro semestre do ano passado desempenho acadêmico superior aos demais estudantes. O dado não prova que isso vá ser sempre assim, mas já indica que o acompanhamento sério dessa experiência pode derrubar alguns preconceitos (A AMEAÇA..., 2004, p. A2).

Outra matéria, publicada no final daquele mesmo ano, evidenciou a melhoria no desempenho acadêmico de alunos cotistas de duas universidades estaduais do Rio de Janeiro (UERJ e UENF) e a Universidade Estadual da Bahia (UNEB): “(...) uma pesquisa da reitoria [da UNEB] mostrou que, após um ano, esses estudantes tiveram nota média 7,7, enquanto os demais tiveram média 7,9." (Сом BOA NOTA..., 2004, p. C1).

As cotas favorecem o acesso de negros à educação superior; entretanto, outras estratégias devem ser desenvolvidas para promover a permanência desses estudantes na universidade de modo a concluírem seus cursos de graduação. É sabido que apenas uma política de acesso não garante conclusão da educação superior, mas apenas aponta possibilidades antes não pertinentes à realidade de estudantes negros e oriundos de escolas públicas. Os estudantes negros da UEMS que entraram pelo sistema de cotas 
BITTAR, M.; ALMEIDA, C. E. M. Mitos e controvérsias sobre a política de cotas...

assim se manifestaram sobre as dificuldades de permanência na Universidade:

\begin{abstract}
... para mim está sendo bem difícil, até tinha desistido semana passada, porque é minha tia que me ajuda, ela me dá os passes, porque se fosse pelos meus pais não dariam conta, minha avó dá o dinheiro do xerox, então assim que eu estou vindo (Entrevista, Aluna B, Enfermagem)
\end{abstract}

A aluna expressa a dificuldade econômica para se manter na instituição e prosseguir com estudos no período diurno, demonstrando que apenas o acesso não favorece a permanência de alunos cujo histórico é de desigualdades sociais, raciais e, principalmente, econômicas. A história brasileira tem, no período escravocrata, uma marca de sua identidade cultural; essa influência interfere nos costumes e manifestações ao longo do tempo e não são atitudes descontextualizadas, mas fundamentadas em uma cultura que perpetua a hegemonia branca e a servidão negra. Devido às raízes dessa questão, a situação de desigualdade entre negros e brancos não é alterada de forma simples e tranqüila, fato comprovado pelas entrevistas, pois os alunos negros oriundos de outros municípios do interior de MS enfrentam dificuldades econômicas para se manter em cursos diurnos. Outro aluno reforça a dificuldade em conciliar estudo e trabalho:

Acho que o econômico é o que lidera, principalmente na UEMS que é matutino, porque fica mais difícil encontrar um emprego para ajudar a família. O econômico é o principal porque a pessoa tem que trabalhar e às vezes não consegue acompanhar projetos, estudar para as provas e ir na faculdade todo o dia também, não consegue acompanhar isso e outro talvez seja passe, escola pública... (Entrevista, Aluno A, Direito)

A UEMS demonstra ciência dessas necessidades por meio de propostas e programas ${ }^{4}$ para favorecer a permanência de alunos negros que in-

${ }^{4}$ Entre essas ações, destacam-se: criação do Núcleo de Estudos Étnico-Raciais NEER; participação na elaboração do Programa Integrado de Ações Afirmativas para Negros - AFROATITUDE; inclusão nos Projetos Pedagógicos de disciplinas sobre questões étnicas e raciais; Projeto de Capacitação da Comunidade Universitária; participação na elaboração 
gressaram pelo sistema de cotas, como a "Criação de Comissão de Acompanhamento e Avaliação da Permanência dos Cotistas da UEMS" (CORDEIRo, 2005), que acompanha o desenvolvimento acadêmico dos alunos e oferece bolsas aos que participam de projetos de pesquisa e extensão. Dessa forma a Universidade apóia e acompanha o desenvolvimento dos estudantes negros, com o intuito de que estes obtenham a conclusão de seus cursos.

\section{Conclusão}

A pesquisa evidenciou que a adoção do sistema de cotas consiste numa ação afirmativa de superação de desigualdades, na direção da conquista da igualdade material ou substancial que é fruto do que se pode chamar de segunda geração de direitos fundamentais, pois ela absorve e amplia o direito processual. Não basta, segundo esse novo paradigma de organização dos poderes públicos, garantir um Estado que seja cego para distinções arbitrárias. É insuficiente vedar que a lei condene o indivíduo com base no grupo em que este se insere segundo padrões naturais ou culturais. Faz-se necessário, implementar, por meio da lei e de instrumentos de políticas públicas, a igualdade de oportunidades, ainda que seja necessário estipular benefícios compensatórios a grupos historicamente discriminados. Este novo paradigma direciona-se a uma noção mutante e militante da igualdade, uma vez que se percebeu a ineficácia do zelo por uma igualdade meramente formal e abstrata, além de estática, que na maioria das vezes aprofunda e perpetua as desigualdades presentes na sociedade. Da ótica ultrapassada do indivíduo genérico, desprovido de cor, sexo, idade, classe social entre outros critérios, agora se busca o indivíduo específico "historicamente situado", objetivando extinguir ou diminuir o peso das desigualdades impostas econômica e socialmente. A consagração normativa dessas políticas sociais representa, pois, um momento de ruptura na evolução do Estado moderno.

do Edital do Programa de Ações Afirmativas para a População Negra nas IES Públicas UNIAFRO; inclusão da UEMS na rede Programas Políticas da Cor - PPCOR/UERJ (CORDEIRO, 2005). 
BITTAR, M.; ALMEIDA, C. E. M. Mitos e controvérsias sobre a política de cotas...

\section{REFERÊNCIAS}

AAMEAÇA DAS COTAS. Folha de São Paulo. São Paulo, 3 de junho de 2004, p. A2.

ALMEIDA, Rogério Lucio. O gigante Negro. In: Boletim Informativo, n. 1418, ano 29, nov. 2003. Disponível em: http://www.ufmg.br/boletim/bol1418/segunda.shtml. Acesso em: $10 / 03 / 2006$

BRANDÃO, C. F. As cotas na universidade pública brasileira: será esse o caminho? Campinas, SP: Autores Associados, 2005. (Coleção Polêmicas do Nosso Tempo)

BOURDIEU, Pierre; PASSERON, Jean Claude. A reprodução. 2.ed. Rio de Janeiro: Francisco Alves, 1982.

COM BOA NOTA, COTISTA PRECISA DE RECURSOS. Folha de São Paulo. São Paulo, 13 de dezembro de 2004, p.C1.

CORDEIRO, Maria José de Jesus A. A UEMS na promoção da igualdade racial. $I^{o}$ Seminário Interinstitucional de Promoção da Igualdade Racial - promover a igualdade valorizando a diferença. UCDB: GEPPES: NEABE, 25 e 26 de novembro de 2005.

FOLHA DE SÃO PAULO. São Paulo, 22 de fevereiro de 2003, C4.

FUNDAÇÃO CULTURAL PALMARES-BR. Disponível em: http://www.palmares. gov.br. Acesso em: 03/07/2005.

GOMES, Joaquim Barbosa. O debate constitucional sobre as cotas. In: SANTOS, Renato Emerson dos; LOBATO, Fátima. (Orgs.). Ações Afirmativas: políticas públicas contra as desigualdades raciais. Rio de Janeiro: DP\&A, 2003.

GOLDEMBERG, José. As cotas nas universidades públicas. Folha de São Paulo. São Paulo, 8 de abril de 2004, p. A3.

GONÇALVES, L.A. Os negros e educação no Brasil. In LOPES, E.M. et al. 500 anos de Educação no Brasil. Belo Horizonte: Autêntica, 2000, p. 325-346.

IBGE. Disponível em: http://www.ibge.gov.br/. Acesso em: 02/12/2005.

JUIZ QUESTIONA POLÍTICA DE COTAS NO PARANÁ. Folha de São Paulo. São Paulo, 15 de fevereiro de 2005, p. C1).

LEI $^{\circ}$ 2.605/03, de 06/01/2003. Dispõe sobre a reserva de vagas para negros nos cursos de graduação na Universidade Estadual de Mato Grosso do Sul e dá outras providências. Disponível em: http://www.pedrokemp.com.br. Acesso em: 23/3/2006.

MEC/INEP/SEEC. Disponível em: http://www.inep.gov.br/superior/censosuperior/sinopse/ default.asp. Acesso em: 3/12/2003.

MEC/INEP. Disponível em: http://www.inep.gov.br/informativo/informativo130.htm. Acesso em: 10 de março de 2006. 
MUNANGA, Kabengele. Políticas de ação afirmativa em benefício da população negra no Brasil - Um ponto de vista em defesa de cotas. Revista Espaço Acadêmico. Maringá: UEM, ano II, n. 22, mar. 2003a. Disponível em: http://www.espacoacademico.com.br/ 022/22cmunanga.htm. Acesso em: 10 de março de 2006.

Políticas de ação afirmativa em benefício da população negra no Brasil: um ponto de vista em defesa das cotas. In: SILVA, Petronilha Beatriz Gonçalves; SILVÉRIO, Valter Roberto (orgs.). Educação e ações afirmativas - entre a injustiça simbólica e a injustiça econômica. Brasília: INEP, 2003b, p. 115-128.

Políticas de Ação Afirmativa em benefício da população negra no Brasil - um ponto de vista em defesa de cotas. In: GOMES, Nilma Lino; MARTINS, Aracy Alves (orgs.). Afirmando direitos - acesso e permanência de jovens negros na universidade. Belo Horizonte: Autêntica, 2004, p. 47-59.

PAIXÃO, Marcelo. Brancos detêm 74\% da renda brasileira. Folha de São Paulo. São Paulo, 20 de novembro de 2003, C3.

Desenvolvimento humano e relações raciais. Rio de Janeiro: DP\&A, 2003.

RIBEIRO, Matilde. Pela promoção da igualdade racial. Folha de São Paulo, São Paulo, 20 de novembro de 2003, A3.

SAAVEDRA, Anita et.al. Somos todos iguais? Escola, discriminação e educação em direitos humanos. Rio de Janeiro: DP\&A, 2003.

UEMS. Disponível em: http://www.uems.br. Acesso em: 2/12/2003.

Texto recebido em 07 maio 2006

Texto aprovado em 25 jun. 2006 